\title{
Revenue sharing models in strategic alliances
}

\author{
Antti Rantala, VTT, antti.rantala@vtt.fi \\ Helena Kortelainen, VTT, helena.kortelainen@vtt.fi
}

\begin{abstract}
Inter-organizational product development is becoming more common as even large manufacturers lack necessary knowhow to develop competitive products without external help. Especially development of products that include complex components, software and artificial intelligence require diverse knowhow, which leads organizations to seek special skills from external sources. Exploiting external stakeholders in product development can induce many benefits such as increase creativity, improve product quality and speed up the product development processes. Although the benefits of utilizing external companies' expertise in product development is well recognized, less is known about how companies share the jointly generated value among each other. This study investigates cases presented in previous literature about companies' risk and revenue sharing arrangements in different industries. Objective of this study is to construct illustrative revenue sharing models that OEMs could utilize when deepening their relationships with technology companies.
\end{abstract}

Keywords: Product Development, Collaboration, Business Model, Revenue Sharing, Strategic Alliance

\section{Introduction}

When companies develop their products, they often face complex problems that require expertise that does not exist in-house (Suominen, Mäenpää \& Breite 2017). Companies are in a transition where innovation is moving out from the organizational boundaries and where innovation networks co-create value (Olsson \& Boch, 2014). Organizations that engage in collaborative R\&D efforts have the opportunity to combine their complementary know-how by facilitating the generation of technological inventions that organizations could not achieve on their own (Belderbos, Cassiman, Faems, Leten \& Van Looy 2014). Interorganizational product development between suppliers and customers has led into improved quality of products, quicker product development processes and decreased product development costs (Saarnilehto, Vesalainen \& Annola 2013).

Software-intensive companies are experiencing a shift from a hardware and product-based business towards a business where software, data, and AI are utilized to offer significantly improved products (Olsson \& Boch 2020). As new technologies emerge and get relevant, companies have to decide whether to hire new staff with the desired skills or to collaborate with external partners that possess the desired competences (Olsson \& Boch 2020). For instance, purchasing softwares in a traditional way can be expensive (Rantala, 2020), and some companies, including OEMs (Original Equipment Manufacturers) and software companies, are interested in creating collaborative business relationships to get the desired competences in their products. 


\section{Issues in Information Systems}

Volume 22, Issue 1, pp.178-187, 2021

Many companies have turned their traditional purchasing relationships into strategic alliances with their suppliers (de Man 2013). The traditional purchasing mindset builds on win-lose thinking: the higher the price paid for a product, the more buyer loses and the supplier gains. However, continuous technology development is changing the market circumstances, and short-term cost savings are becoming less important than innovation capabilities and flexibility (de Man 2013). Strategic alliance can be defined as the cooperative arrangement between two or more firms that exchange or share resources for competitive advantage (Huang, Chen, Liu \& Tzeng 2010). In a strategic alliance, partners can pool their strengths and resources together to share risks, achieve technology innovation and improve performance (Fahimullah, Faheem \& Ahmad 2019). The increasing uncertainty, complexity of knowhow and costs of product development drive firms to pool their resources and enter into joint-development contracts involving the sharing of product revenues and development costs between partners (Bhaskaran \& Khrisnan 2009). For example, BMW has formed an alliance with technology companies to develop autonomous driving systems (Zhao, Tan \& Liu 2020).

Olsson and Boch (2014) noted that identifying a business model that is profitable for all value co-creators can be difficult. Some businesses that are interested in strategic collaboration with their suppliers struggle in finding a suitable business model that could enable a win-win situation for all partners. An example on such business are major OEMs including vendors providing machinery utilized in the logistic chains. Mobile working machines are increasingly automated, and computers assist the operators in their daily tasks. Data, software and artificial intelligence (AI) are at the core of the transformation to more advanced machines (Olsson \& Boch 2020).

Because OEMs are becoming more and more dependent on their technology suppliers, there is a need to understand what kind of collaborative business models can be used between OEMs and technology suppliers. A study made by Rantala (2020) implied that various business managers were interested in forming strategic alliances with their software suppliers, but complexity of forming risks and benefits sharing business models were seen as a barrier for such collaboration. In addition, companies lack for practical examples of such models. The collaboration between major OEMs and local software suppliers is often characterized by some power asymmetry and power imbalance may prevent intensive collaboration as the actor in a dominant position may not be willing to form collaborative relationships with other companies (Kähkönen, 2014). There is also a lack of discussion and collaboration between software developers and domain experts (Ahonen et al., 2020). In this paper, we study what kind of revenue sharing models have been deployed and model the revenue streams of successful business partnerships. Demonstrating successful business examples creates an understanding of the nature of the phenomenon and support the discussion on their benefits in an ecosystem around work machines in the port domain.

\section{Background and literature review}

The increasing technological complexity has made external expertise indispensable to OEMs. Companies can gain competitive advantage by combining the skills offered by component and system providers and by other specialist firms in the product development processes (Saarnilehto et al. 2013). Inter-organizational collaboration has increased in recent years as even large OEMs do not possess all the necessary skills inhouse for developing products where a wide range of expertise and different forms of know-how are required. As big OEMs are developing complex products, small specialist companies are becoming more directly involved in product development processes (van der Meer Kooistra \& Scapens, 2015).

According to a study made by Olsson \& Boch (2020), many companies look to partner with companies specializing in software, data, and Artificial Intelligence (AI) as these help them solve customer problems in areas where they themselves do not possess the domain knowledge. Increasing number of companies 


\section{Issues in Information Systems}

Volume 22, Issue 1, pp.178-187, 2021

open up their products for functional extensions by third party developers. Concurrently, companies need to pay attention how to strategically align with the ecosystem of which it is part (Olsson \& Boch 2014). Figure 1 represents the building blocks of a business ecosystem between software intensive companies.

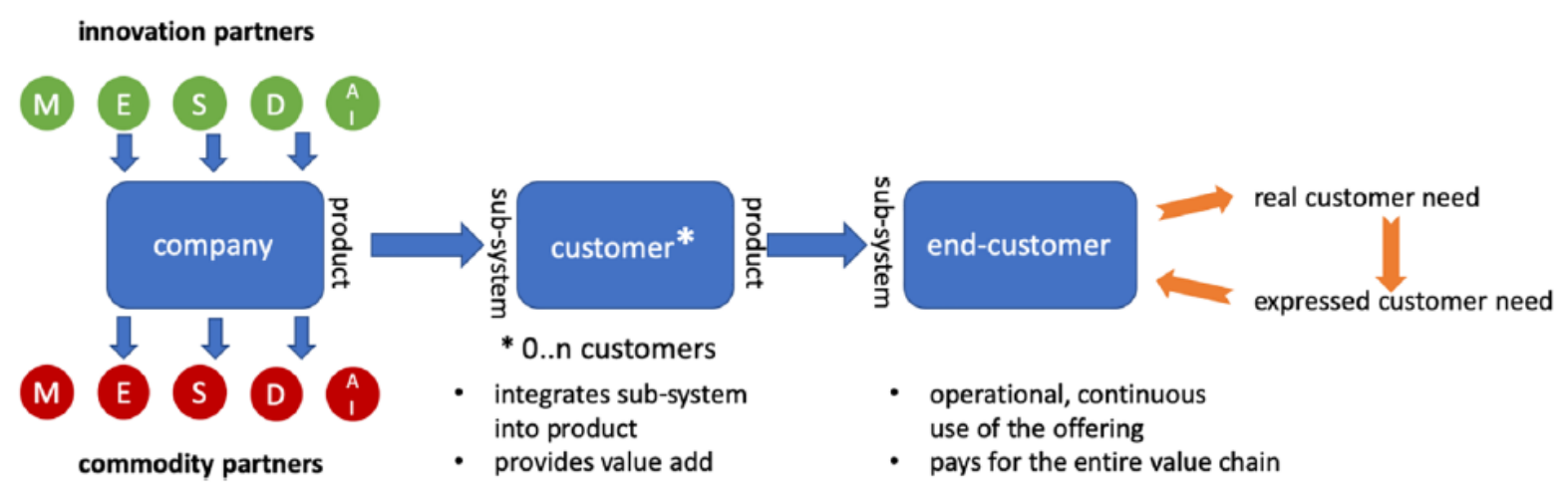

Figure 1. Building blocks of a business ecosystem (Olsson \& Boch 2020)

Software intensive systems companies usually has innovation partners and commodity partners. These partners can have a focus on mechanics (M), electronics (E), software (S), data (D), artificial intelligence (AI), or a combination of these. As new technologies emerge and get relevant, a company has to decide should they train their existing staff, hire new employees with the desired skills or to collaborate with external partners (Olsson \& Boch 2020). If a company decides to collaborate with an external partner, there are many types of relationships that can be formed. In sharing relationship, two companies create value by combining similar capabilities to reach greater scale or network effects (de Man \& Luvison 2019). In specialization relationship, companies from different industries create value by combining complementary capabilities (de Man \& Luvison 2019). If collaboration aims to develop new technological solutions, specific contracts regarding risk and revenue sharing are essential (Saarnilehto et al., 2013). Novel forms of collaboration drive companies to innovate also their business model that lays the foundation for how revenue is generated. Business model innovation is rapidly becoming the key differentiator for companies across domains (Olsson and Bosch 2020).

A business model describes the rationale of how an organization creates, delivers, and captures value (Osterwalder \& Pigneur 2010). It also outlines the architecture of revenues, costs, and profits associated with the business enterprise delivering that value (Teece 2010). Hacklin, Bjorkdahl \& Wallin (2017) wrote that companies with proactive business model capture and generate higher value in dynamic market as compared to reactive business models. A study made by Anwar (2018) suggests that business model innovation is a significant driver that contributes positively to firm's performance and competitive advantage. Therefore, as companies are deepening their relationships with their product development partners, new business models should also be considered. de Man \& Luvison (2019) noted that collaborative business models should meet the interests of all partners to be successful. It is essential to generate win-win situation in business collaboration in order to keep all parties satisfied and fully involved in the common goals (Sjödin et al. 2020).

\section{Study context and research method}

This study is a part of the ongoing Finnish national research project 'Operational excellence and novel business concepts for autonomous logistic systems in ports' (AUTOPORT). The project is a co-innovation project that aims to path the way towards automated operations in ports by developing model-based design flow, operational excellence, and models for sharing incurring costs and benefits. AUTOPORT is 


\section{Issues in Information Systems}

Volume 22, Issue 1, pp.178-187, 2021

conducted in close co-operation with the research organizations and the company network that consists of OEMs, ICT solution providers and engineering companies. In port terminals and logistics the trend towards computer-assisted and increasingly automated machinery operations is evident (Heikkilä et al. 2020). Thus, OEMs are also looking for practical models for inter-organisational collaboration but feel challenged by the expected complexity of such models.

This study aims at increasing understanding of challenges and at proposing solutions for sharing benefits and costs in product development ecosystems. Our aim is to demonstrate different business models in a practical manner. In order to understand how businesses share risks and co-create value in strategic alliances, we adopted case-study about revenue-sharing arrangements of three different business cases which were identified in the literature survey. The three cases (Table 1) were chosen as they represent different situations where collaborative business models with revenue sharing contracts were beneficial for all partners. The selected case companies had formed successful strategic alliances and revenue sharing arrangements with their stakeholders. As such, they are relevant to the AUTOPORT ecosystem and offer a practical way of demonstrating the impact of different business models to risk and revenue sharing.

The study applies qualitative case study research strategy (e.g., Eisenhardt, 1989; Yin, 2003). This approach was chosen to understand the complex phenomenon of inter-organizational collaboration and its impact on business models and revenue streams (e.g., Yin, 2003). In case study research, rich and intensive information is collected from a single case or a small group of selected cases (Hirsjärvi, Remes and Sajavaara, 2014). Table 1 lists the cases presented in this study.

Table 1. Cases presented in the study

\begin{tabular}{|l|l|}
\hline Alliance partners & Case \\
\hline FEI, NTS, Sioux \& Benchmark & $\begin{array}{l}\text { Vertical co-development project with shared costs and } \\
\text { revenues }\end{array}$ \\
\hline Sara Lee/DE \& Philips & Horizontal co-development project with shared revenues \\
\hline Blockbuster \& Movie studios & $\begin{array}{l}\text { Vertical revenue sharing arrangement through a supply } \\
\text { chain }\end{array}$ \\
\hline
\end{tabular}

Although the benefits of utilizing external companies' expertise in innovation processes is well recognized, less is known about how companies share the jointly generated value among each other. In the following chapter, we model different revenue sharing cases and demonstrate the drivers and benefits of these arrangements.

\section{Modeling the revenue streams}

\section{The Phenom case}

The Phenom case is a great example how companies with different expertise combined their skills to create new product to market (Van der Meer-Kooistra \& Scapens 2015). A revenue sharing product development alliance was formed in order to co-develop a novel desktop electron microscope to the markets. Instead of the OEM developing the product itself and outsourcing specific tasks to subcontractors, the suppliers became co-developers and shared development costs with the OEM. The main parties of the project were four companies, namely FEI (as the OEM), NTS (the mechatronics developer), Sioux (the software developer) and Benchmark (the electronics developer). FEI, NTS and Sioux adapted a risk-reward model, which meant that NTS and Sioux were to be paid for their development work through a share of the profits from FEI's sales of the Phenom. Benchmark was unwilling to share risks in this way and instead it undertook its development work for a fixed fee which was agreed in advance. Figure 2 illustrates the 


\section{Issues in Information Systems}

Volume 22, Issue 1, pp.178-187, 2021

developer companies' profit sharing arrangement. The risk-reward parties wanted the project to be developed as quickly as possible so that they could start recovering their investments. Therefore, they put notable effort into achieving the common goals of this product development project.

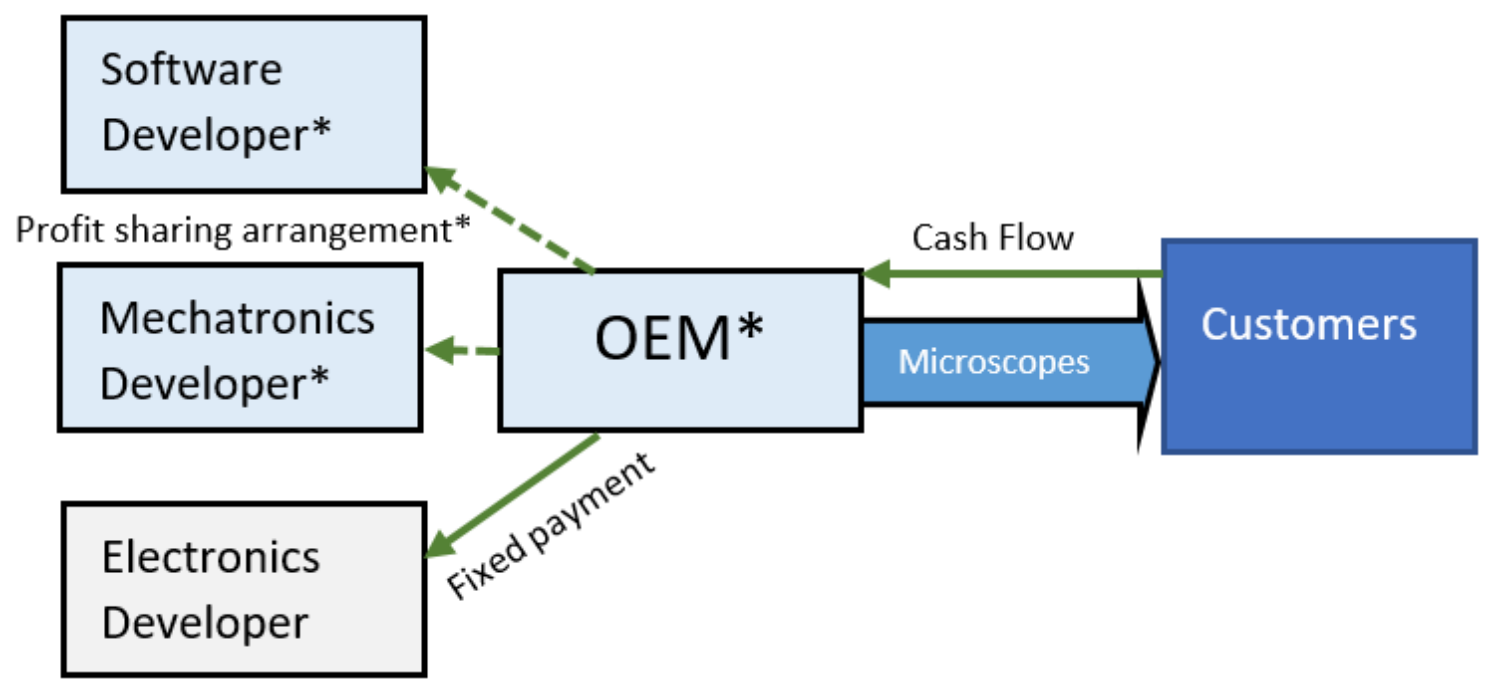

Figure 2. Phenom's revenue sharing arrangement

\section{The Senseo Case}

In the Senseo case Philips and Sara Lee/De created a new way of making coffee (de Man 2013). Philips was specialized in electronic machines and Sara Lee/DE was a coffee bean company. They formed a successful strategic alliance, where they developed a novel concept for making coffee by using coffee pods which enabled making only one cup of filtered coffee instead of a whole pot. Philips was responsible of developing the coffee machine and Sara Lee/DE was responsible of the coffee pods. As a result of the collaboration, Philips produced a Senseo coffee machine, where one cup of coffee was possible to make using innovative pre-packed coffee pods. The coffee machine was sold at relative low price, so Sara Lee/DE shared some of the revenues generated from the coffee pods to compensate the low margins of Philips' coffee machines. Figure 3 demonstrates the revenue sharing arrangement of this strategic alliance.

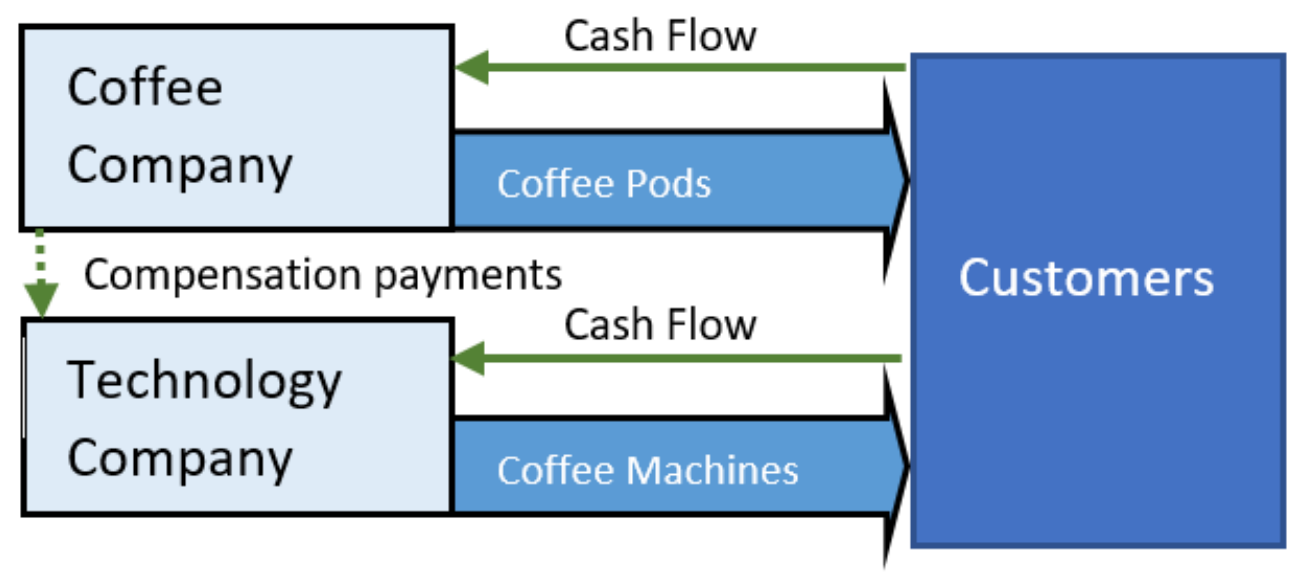

Figure 3. Senseo's revenue sharing arrangement 


\section{Issues in Information Systems}

Volume 22, Issue 1, pp.178-187, 2021

\section{The Blockbuster Case}

Blockbuster is a video rental firm which problem was that they couldn't afford to stock the number of movies it needed to serve all their customers, because their suppliers charged a high initial price for the movies (Cachon \& Lariviere 2001). Blockbuster was losing sales whenever customers visited to their store only to find out that all copies had already been checked out. Blockbuster solved the problem by changing the way it paid its suppliers. They started to buy the movies at a discounted price and paying share of their movie rental revenues to their video supplier in order to compensate the low purchasing price. That arrangement enabled Blockbuster purchase more tapes, which enabled renting increased number of movies to their customers. This arrangement generated more revenues for all stakeholders. Also, the customers were more satisfied because of the increased number of available video copies. Figure 4 illustrates the cash flows of the revenue sharing arrangement.

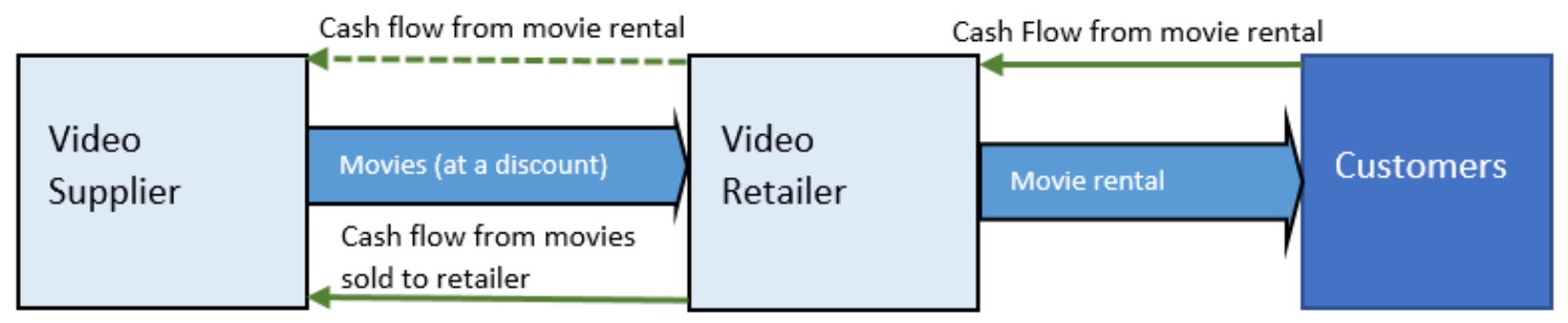

Figure 4. Blockbuster's revenue sharing arrangement

\section{Discussion}

This paper presented three ways to share risks and revenues in strategic alliancess. In the Phenom case, the OEM wanted to collaborate with its suppliers in the product development. Organizations that engage in collaborative product development can to combine their complementary know-how and generate technological inventions that they could not achieve on their own (Belderbos et al.2014). In addition, collaborative product development between suppliers and customers has led into improved quality of products, quicker product development processes and decreased product development costs (Saarnilehto et al., 2013). The OEM also wanted to share the risks with its suppliers, because development of new products usually include some uncertainties. The uncertainty, complexity of knowhow and costs of product development are drivers that make firms to pool their resources and enter into joint-development contracts involving the sharing of product revenues and development costs (Bhaskaran \& Khrisnan 2009). So, suppliers agreed to carry out some of the costs of the product development project in order to a gain share of the future revenues. This way the OEM reduced its financial risks of the product development project and created incentives for its suppliers to work efficiently towards common goals.

In the Senseo case Sara Lee/DE and Philips created a novel way of making only one cup of filtered coffee instead of a whole pot. Sara Lee/DE didn't have capabilities to build a coffee machine on its own, so they formed a horizontal strategic alliance with Philips. By doing that, they were able pool their strengths and resources together to achieve technology innovation (Fahimullah et al. 2019). By combining their knowledge, they were capable of creating a completely unique product into markets. To ensure that the collaboration was fair for both companies, they agreed to share some of the profits generated by Sara Lee/De's coffee pods. In collaborative business models, it is important to generate win-win situations for all parties to keep them fully involved in the common goals (Sjödin et al. 2020). 


\section{Issues in Information Systems}

Volume 22, Issue 1, pp.178-187, 2021

In the last case, Blockbuster wanted to ensure that they have enough movies in their stock to serve as many customer as possible. Their problem was high movie prices set by movie studios which restricted their capabilities to buy enough movies in their stock. Blockbuster solved their problem by making an arrangement with movie studios in which they purchased movies at a discounted price and shared the video rental revenues with the movie studios. By doing this, Blockbuster was able to get more movies in their stock and thus they could serve more customers, resulting in more revenue. It was lucrative for all parties to create a business model where everyone benefited directly from increased sales. Cachon \& Lariviere (2001) consider that this model would work in other industries too when certain conditions are met. Fist, the cost to produce the additional units must be less than the incremental revenue they generate. This condition could be met for example in software industry. Software products usually have really high initial costs, but the reproduction cost for a ready-made software is practically non-existent (Ojala 2012). The second criterion is that the administrative burden associated with revenue sharing must be small enough that the cost of new business model doesn't eat up all the gains (Cachon \& Laviere, 2001).

Modern ports use innovative technologies and automation to optimize their operations. Rapidly changing business environments require port logistics OEMs and suppliers to adapt to new demands, and therefore their business models need to reflect the need for change. As port logistics OEMs are developing new working machines with increasing level of automation and technological capabilities, technology suppliers and other stakeholders may have an essential role in the OEMs' product development processes. In this process, there is also a clear need for reducing the costs of software development in mobile work machine applications (Ahonen et al. 2020). Sharing costs and revenues of product development processes could enhance companies' willingness to combine their resources and thus improve the quality of products and speed up the product development. According to study made by de Man \& Luvison (2019) operationalizing of a collaborative business model may be complex because it needs to meet the interests of all partners.

This paper introduced cost and revenue sharing arrangements from different industries, and proposes that they could have a significant role in boosting port logistics OEMs' innovation capabilities. Forming strategic alliances with technology providers could be an excellent method to share risk and benefits in complex innovation partnerships. In addition, alliances could provide a fair playing ground for OEMs and smaller technology companies by balancing the power asymmetries which have been common issue in relationships between large and small companies (Kähkönen 2014). Deep and fair collaboration with companies with complementary capabilities could boost the knowledge creation that is needed for the future work machine development in various industries, including port logistics domain.

\section{Conclusions}

Purpose of this paper was to increase understanding of collaborative business models by investigating and modelling revenue sharing arrangements of different strategic alliances. Business cases demonstrated the benefits that properly formed strategic relationships can induce. In the Phenom case, cost and revenue sharing arrangement among OEM and its suppliers, enabled development of an innovative electronic microscope. In the Senseo case, sharing revenues of the coffee pods generated a win-win situation for both partners. In the Blockbuster case, after the creating the revenue sharing arrangement, all stakeholders were better off. As a conclusion, strategic alliances and revenue sharing contracts can boost innovation and profitability of businesses if the right conditions are met.

Inter-organizational product development is becoming indispensable for port logistics OEMs as automation and technological demands are increasing in the markets. Forming risks and benefits sharing strategic alliances with technology suppliers could be an excellent tool for enhancing innovation and reducing companies' product development risks. As a result of this study, we encourage OEMs to innovate their 


\section{Issues in Information Systems}

Volume 22, Issue 1, pp.178-187, 2021

business models and to consider forming product collaborative business models with their technology suppliers.

\section{Limitations and Directions for future research}

This paper illustrated three successful collaborative business models from the literature. However, this study did not address various risks and barriers concerning collaborative business models. Examples about unsuccessful risk and revenue sharing business cases would have added depht into this paper. Future research is needed to understand how the learnings from the successful examples could be tranfserred and applied in the practical inter-organizational collaboration between OEMs and technology providers. Also, experiences about other revenue sharing arrangements such as lump sums, thresholds and caps and could be researched more in practice.

\section{Acknowledgments}

This paper is conducted as a part of VTT Technical Research Centre of Finland's AUTOPORT project. AUTOPORT - Operational excellence and novel business concepts for autonomous logistic systems in ports - is a co-innovation project consortium which objective is to pave the way towards business renewal and operational excellence by developing ecosystem level approaches for logistic robot systems.

\section{References}

Ahonen, T., Kortelainen, H. \& Rantala, A. (2020) Towards Digitalized and Automated Work Processes in Port Environments. VEHITS 2020: Proceedings of the 6th International Conference on Vehicle Technology and Intelligent Transport Systems. SciTePress, Vol. 1. pp. 535-540

Anwar, M. (2018). Business Model Innovation and SMEs Performance - Does Competitive Advantage Mediate? International Journal of Innovation Management, 22(07).

Belderbos, R., Cassiman, B., Faems, D., Leten, B. \& Van Looy, B. (2014) Co-ownership of property Exploring the value appropriation and value creation implications of co-patenting with different partners. Research Policy, 43(5), 841-852. https://doi.org/10.1016/j.respol.2013.08.013

Bhaskaran S. \& Krishnan V. (2009). Effort, revenue, and cost sharing mechanisms for collaborative new product development. Management Science. 55(7), 1152-1169.

Cachon, G. P., \& Lariviere, M. A. (2001). Turning the supply chain into a revenue chain. Harvard Business Review, 79(3), 20-21.

de Man, A. (2013). Alliances: An Executive Guide to Designing Successful Strategic Partnerships. Chichester: John Wiley and Sons Inc

de Man, A. \& Luvison, D. (2019) Collaborative business models: Aligning and operationalizing alliances. Business Horizons, 62(4) 473-482

Eisenhardt, K. M. (1989) 'Building Theories from Case Study Research', The Academy of Management Review. Academy of Management, 14(4), 532-550. 


\section{Issues in Information Systems}

Volume 22, Issue 1, pp.178-187, 2021

Fahimullah, M., Faheem, Y. \& Ahmad, N. (2019). A bi-objective game-theoretic model for collaboration formation between software development firms. PLoS ONE, 14(7).

Hacklin, F, J Bjorkdahl and MW Wallin (2017). Strategies for business model innovation: How firms reel in migrating value. Long Range Planning, 51(1), 82-110.

Heikkilä, E. Malm, T., Tiusanen, R., \& Ahonen, T. (2020) Safety and Dependability of Autonomous Systems in Container Terminals: Challenges and Research Directions. VEHITS 2020:

Proceedings of the $6^{\text {th }}$ International Conference on Vehicle Technology and Intelligent Transport Systems. SciTePress, Vol 1., 528-534

Hirsjärvi, S., Remes, P. and Sajavaara, P. (2014) Tutki ja kirjoita. Helsinki: Tammi

Holmström-Olsson, H. \& Bosc, J. (2020). Going Digital: Disruption and Transformation in SoftwareIntensive Embedded Systems Ecosystems. Journal of Software: Evolution and Process, 32(6), 124.

Holmström-Olsson, H. \& Boch, J. (2014). Ecosystem-Driven Software Development: A Case Study of the Emerging Challenges in Inter-organizational R\&D. International Conference of Software Business, Paphos.

Huang JJ, Chen CY, Liu HH, Tzeng GH (2010). A multiobjective programming model for partner selection-perspectives of objective synergies and resource allocations. Expert Systems with Applications. 37(5), 3530-3536.

Kähkönen, A.K. (2014). The influence of power position on the depth of collaboration. Supply Chain Management: An International Journal, 19(1), 17-30.

Ojala, A. (2012). Comparison of different models in SaaS. In E. Prakash (Ed.), Proceedings of $5^{\text {th }}$ Computer Games, Multimedia \& Allied Technology Conference (CGAT 2012) 120-23. Singapore: GST

Osterwalder, A., and Y. Pigneur. (2010). Business model generation: A handbook for visionaries, game changers, and challengers. Hoboken, NJ: John Wiley \& Sons.

Rantala, A (2020) Inter-organizational collaboration in software product development. Masters' Thesis, University of Vaasa. http://urn.fi/URN:NBN:fi-fe202003128003

Saarnilehto, V., Vesalainen, J. \& Annola, V. (2013). Monimuotoinen verkosto - johtamista ja juridiikkaa. Helsinki: Kauppakamari (in Finnish)

Sjödin, D., Parida, V., Jovanovic, M. \& Visnjic, I (2020). Value Creation and Value Capture Alignment in Business Model Innovation: A Process View on Outcome-Based Business Models, Journal of Product Innovation Management, 37(2), 158-183.

Suominen A., Mäenpää S., Breite R. (2017) Expert Knowledge Integration-A Systematic Approach for Multi-stakeholder Innovation. In: Vesalainen J., Valkokari K., Hellström M. (eds) Practices for Network Management. Palgrave Macmillan, Cham. https://doi.org/10.1007/978-3-319-49649-8_9 


\section{Issues in Information Systems}

Volume 22, Issue 1, pp.178-187, 2021

Teece, D. J. (2010). Business models, business strategy and innovation. Long Range Planning, 43, 172194.

van der Meer-Kooistra, J. \& Scapens, R. (2015) Governing product co-development projects: the role of minimal structures. Management Accounting Research, 28, 68-91.

https://doi.org/10.1016/j.mar.2015.05.001

Yin, R. K. (2003) Case Study Research: design and methods. Sage, Thousand Oaks (CA).

Zhao, F., Tan, H. \& Liu, Z. (2020) Analysis of the Business Models of the Intelligent and Connected Vehicle Industry. International Conference on Traffic and Logistic Engineering. MATEC Web Conf, Vol 325 